\title{
Outcome of 'CDC Kerala' Early Stimulation Model on Neurodevelopment of Late Preterm Infants
}

\author{
Ashwini Nachiket Kulkarni ${ }^{1}$, Babu George ${ }^{2 *}$ and Deepa Bhaskaran ${ }^{3}$ \\ ${ }^{1}$ Developmental \& Behavioural Pediatrics, Child Development Centre, India \\ ${ }^{2}$ Child Development Centre, Medical College, India \\ ${ }^{3}$ Developmental Pediatrics, Medical College, India
}

Submission: November 24, 2016; Published: February 17, 2017

*Corresponding author: Babu George, Director, Child Development Centre (CDC), Medical College, India, Tel: 914712553540; Email cdckerala@rediffmail.com

\begin{abstract}
There is increasing evidence that late preterm babies (Gestational Age 34-0/7wks to 36-0/6 wks) are at increased risk of short term developmental morbidities as compared to term counterparts. Cochrane review had shown that early intervention programs for late preterm infants have a positive influence on motor and cognitive development on short-medium term. Early intervention programs like NIDCAP (Newborn Individualized Developmental Care \& Assessment Program), IHDA (Infant Health \& Development Program) are best evaluated. Parent based studies have shown positive influence on neurodevelopment outcome. Present study assesses the outcome of parent based early stimulation model on neurodevelopment of late preterm infants by corrected age of 12 months.

Keywords: Late preterm babies; Neurodevelopment outcome; Early stimulation; Parent based intervention; Developmental screening tools; Developmental assessment scale for Indian infants

Abbreviations: CDC: Child Development Centre; LP: late Preterm; DASII: Developmental Assessment Scale for Indian Infants; DQ: Deviation Quotient; MeDQ: Mental Deviation Quotient, MoDQ: Motor Deviation Quotient, BSID: Bayley Scales of Infant Development; TDSC: Trivandrum Developmental Screening Chart; DDST II: Denver Developmental Screening Test; A T angles: Amiel-Tison angles
\end{abstract}

\section{Introduction}

The near term terminology has been replaced by late preterm for babies born between34-0/7 to 36-6/7Weeks' of gestational age. This emphasizes that last 6 weeks of gestation represent critical period of growth and development. Studies have shown that these babies are at three times higher risk for morbidity and mortality than their term counterparts [1,2]. Indian study done by Wagh \& Jain reported higher neonatal morbidities in LP babies like need for resuscitation, hypoglycemia, feeding problems, sepsis and hyper bilirubinemia than term controls. They shared concerns of growth and development at 3 months of corrected age in these babies [3]. An inverse relationship between gestational age and risk of developmental delay at 18 months of corrected age was found by Luisa et al. [4].

With better understanding of importance of early enrolment of these babies in early stimulation programmes, their Neurodevelopment outcome has improved [5,6]. Systematic review done by Orton et al. gives account of various early intervention models for these babies [7]. CDC model of early stimulation is parent based, home cantered model which has shown its effectiveness in RCT [8]. Present study assesses effectiveness of this model on Neuro developmental outcome of LP infants.

\section{Materials and Methods}

Retrospective, cross sectional analysis of enrolled cases between March \& April 2014 which were followed up to 12months of corrected age at CDC, Kerala.

A. Inclusion criteria: LP Infants (Gestational age 34-0/7 to 36- 6/7 weeks) attending CDC Newborn Follow up clinic.

B. Exclusion Criteria: Major congenital anomalies, visual and hearing impairments.

C. Sample Size: 53 late preterm babies.

D. Intervention \& monitoring:

i. CDC model of early stimulation (ES) monthly till 12 months of Corrected Age

ii. CDC model ES is indigenous, mother oriented program 
designed for babies 0-12months, executed by multidisciplinary team. Its effectiveness is proven in RCT across all birth weight groups [8].

iii.Developmental Screening Tools - TDSC, DDST II, AT angles, $\mathrm{CDC}$ grading of major motor milestones.

iv.Simultaneous assessment of vision, hearing, lactation and feeding was done.

v.Home program: Hands on training on ES techniques encompassing all developmental domains to mother/ care giver and encouraged to do the same many times at home.
vi.Outcome Measure: Evaluation by DASII at 3-5 months ( $1^{\text {st }}$ DASII) \& 12 months ( $2^{\text {nd }}$ DASII) of corrected age- Mental age, Motor age \& deviation quotients derived. MeDQ, MoDQ value 80 and above were taken as normal as and less than 80 as abnormal.

vii.Developmental Assessment Scale for Indian Infants (DASII) is an Indian standardized adaptation of BSID to assess motor, cognitive development of children up to 30 months of age.

Statistically analyzed with variables - weight, gestational age, National Neonatology Forum (NNF- India) risk factors, parent education and socioeconomic class (Table 1).

Table 1: National Neonatology Forum- India risk factors \& abnormal deviation Quotients.

\begin{tabular}{|c|c|c|c|}
\hline \multicolumn{1}{|c|}{ NNF Risk F } & Mild (n=15) & Moderate (n= 14) & Severe (n= 24) \\
Abnormal & & & \\
\hline Deviation Quotient & $3(10 \%)$ & $6(43 \%)$ & $9(38 \%)$ \\
\hline $1^{\text {st }}$ Mental Deviation Quotient & 0 & 0 & $1(4 \%)$ \\
\hline $2^{\text {nd }}$ Mental Deviation Quotient & $3(10 \%)$ & $7(50 \%)$ & $13(54 \%)$ \\
\hline $1^{\text {st }}$ Motor Deviation Quotient & 0 & $1(7 \%)$ & $3(12.5 \%)$ \\
\hline $2^{\text {nd }}$ Motor Deviation Quotient & & \\
\hline
\end{tabular}

Babies with mild and moderate National Neonatology Forum- India risk factors had less abnormal Deviation Quotient.

Results

A.Total 53 babies satisfied inclusion exclusion criteria. 53\% (28) were males and $47 \%$ (25) were females. $40 \%$ (21) babies were normal at 3, 12 months. With respect to socioeconomic class $43 \%$ subjects were BPL (Below Poverty Line), 57\% were APL (Above Poverty Line). No parent was illiterate.
B.Mother Education- $10^{\text {th }}$ std- 2, $12^{\text {th }}$ std- 25, Graduation- 25, Post graduation- 1

C.Father Education- $10^{\text {th }}$ std- $1,12^{\text {th }}$ std- 21, Graduation- 27, Post graduation- 4

D.Birth weight \& Deviation quotients of DASII- (Table 2)

Table 2: Birth weight \& Deviation quotients of Developmental Assessment Scale for Indian Infants.

\begin{tabular}{|c|c|c|c|c|c|c|}
\hline \multirow{2}{*}{ Quotient } & \multicolumn{2}{|c|}{$<1.5 \mathrm{~kg}(\mathrm{n}=9)$} & \multicolumn{2}{|c|}{$1.5-2.5 \mathrm{~kg}(\mathrm{n}=37)$} & \multicolumn{2}{|c|}{$>2.5 \mathrm{~kg}(\mathrm{n}=7)$} \\
\hline & Normal & Abnormal & Normal & Abnormal & Normal & Abnormal \\
\hline $\begin{array}{l}\text { 1st Mental } \\
\text { Deviation } \\
\text { Quotient }\end{array}$ & 7 (78\%) & $2(22 \%)$ & $22(60 \%)$ & $15(40 \%)$ & $5(72 \%)$ & $2(28 \%)$ \\
\hline $\begin{array}{l}\text { 2nd Mental } \\
\text { Deviation } \\
\text { Quotient }\end{array}$ & 8 (89\%) & $1(11 \%)$ & $35(95 \%)$ & $2(5 \%)$ & $7(100 \%)$ & 0 \\
\hline $\begin{array}{l}\text { 1st Motor } \\
\text { Deviation } \\
\text { Quotient }\end{array}$ & $3(33 \%)$ & $6(67 \%)$ & $20(55 \%)$ & 17 (45\%) & $6(86 \%)$ & $1(14 \%)$ \\
\hline $\begin{array}{c}\text { 2nd Motor } \\
\text { Deviation Quotien }\end{array}$ & 8 (89\%) & $1(11 \%)$ & $32(87 \%)$ & $5(13 \%)$ & $7(100 \%)$ & 0 \\
\hline
\end{tabular}

As the birth weight increases, percentage of abnormal Deviation Quotient decreases. 
E. As the birth weight increases, percentage of abnormal DQ decreases.

F. All babies with weight $>2.5 \mathrm{~kg}$ had normal Me, Mo DQ at 12 months.

G. Small for Gestational Age (SGA)/ Appropriate for Gestational Age (AGA) \& Deviation Quotients of DASII- (Figure1)

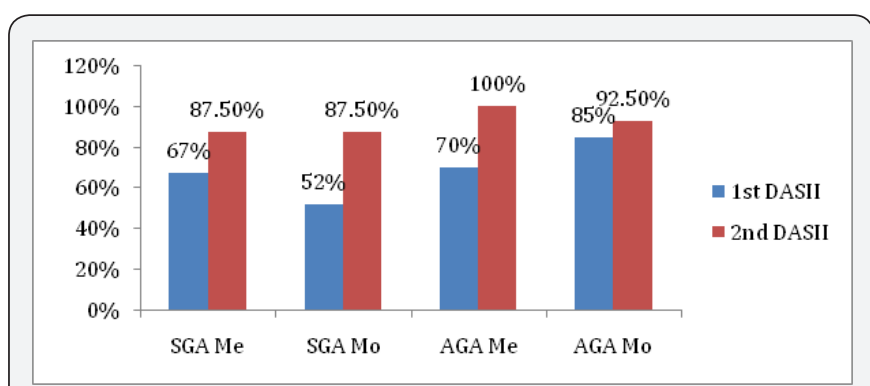

Figure 1: SGA/ AGA Babies \& Normal Deviation Quotient.

H. SGA babies were $75 \%$. Abnormal DQ were more common than in AGA babies. Improvement in DQ at 12 months was more with AGA babies than SGA babies (DQ improvement in SGA- Mo 87.5\%, Me 87.5\%, AGA Mo 92.5\%, Me 100\%).

I. Gestational age \& Deviation quotients of DASII-

J. 34wk (28\%), 35 (34\%), 36wk (38\%). DQ improvement more as gestational age advances. Improvement in MeDQ at 34 wks$50 \%, 36$ wks- $100 \%$, MoDQ at 34 wks- 50\%, 36 wks- $80 \%$.

K. NNF risk factors \& deviation Quotients-

L. Common Risk factors PROM (13 babies), Absent/ reversal EDF 8, Shock 3, Ventilation 3, hypoglycemia 3, Eclamsia 3, Jaundice 3, multiple pregnancy 2.

M. 7 Babies continued abnormal DQs at $12 \mathrm{~m}$ - reversal/ absent end diastolic flow, prolonged ventilation, IVH grade II- III, low birth weight \& PROM.

N. Improvement in Mental Outcome at 12 months- (Figure 2).

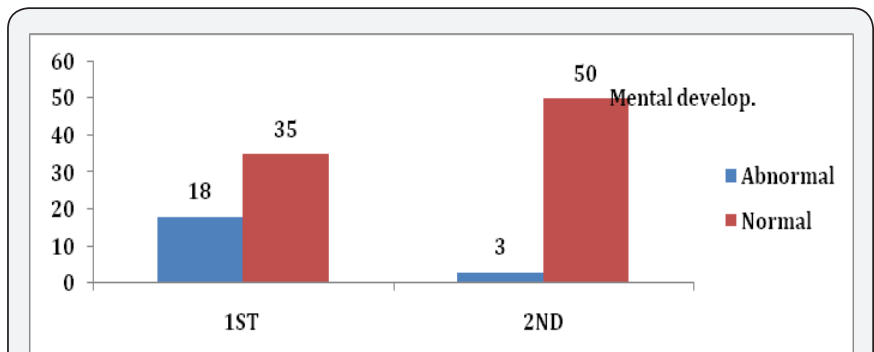

Figure 2: Mental Deviation Quotients at 12 months.

O.Out of 18 babies with abnormal MeDQ at 1st DASII, 16 babies normalized by 12 months.

P.94\% babies had normal Me DQ at $12 \mathrm{~m}$.

Q. Improvement in Motor Outcome at 12 months- (Figure 3).

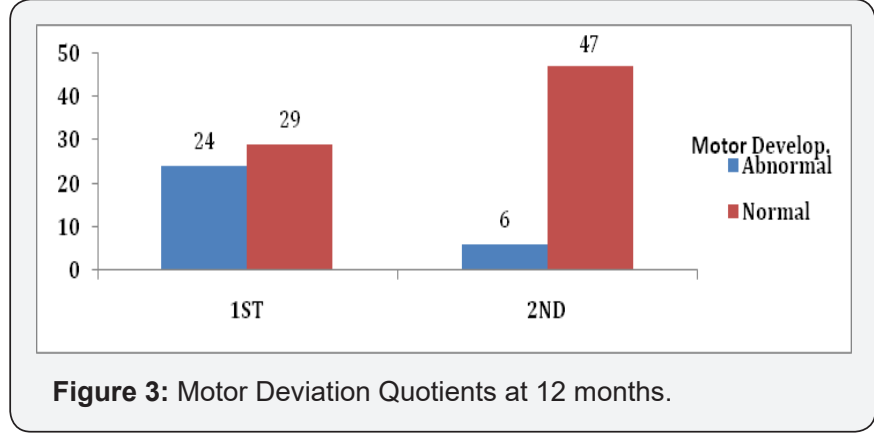

R.Out of 24 babies with abnormal MoDQ at 1st DASII, 20 Normalized by $12 \mathrm{~m}$.

S.89\% babies had normal Mo DQ at $12 \mathrm{~m}$.

\section{Discussion}

Neurodevelopmental outcome in LP infants predominantly depends upon cause of prematurity, SGA/ AGA, associated risk factors $[1,2,9]$. High percentage of SGA babies was observed in our study, similar to findings of Lackman et al. [10]. With increasing birth weight \& gestational age, Neuro developmental outcome of LP infants improved in our study. The same was observed by Schonhaut et al. \& Carrie et al. [4,11].

7 Children who continued to have below average DQs at $12 \mathrm{~m}$ were having severe risk factors. A similar observation was made by Engle et al. [12]. Review of parent based Early Intervention RCTs show positive, clinical, meaningful effects on cognitive and social development of LP infants $[7,12,13]$. CDC ES model starting from stimulation at NICU, lactation management, multisensory stimulation, activities based on developmental milestones has shown improvement in psychomotor functioning at one year, better parent child bonding in at risk babies [8].

\section{Conclusion}

A. Early stimulation pivoting around parent-child in LP babies has positive influence on Neurodevelopmental outcome at 12 months of corrected age.

B. Late preterm is a population at risk, to be monitored.

C. Association between NNF risk factors, primary cause of prematurity and short term Neurodevelopment outcome in LP infants need to address with larger sample size prospective study.

\section{Acknowledgement}

Rajee Krishnan Ramkrishnan Unnithan, Developmental Therapist, Lekshmi Madhavan Amritham,Preschool Teacher, CDC, Medical College, Thiruvanathapuram.

\section{References}

1. Amir Kugelman, Andrew AC (2013) Late Preterm Infants: Near Term But Still in a Critical Developmental Time Period. Pediatrics 132(4): 741-751.

2. Tonse NK (2013) Moderately Preterm, Late Preterm and Early Term Infant: Research Needs, Clin Perinatol 40(4): 791-797. 
3. Amarjeet SW, Naveen J (2012) Comparison of neonatal morbidities of late preterm with term born babies. J of Pharmaceutical and Biomedical Sciences 15(15): 1-6.

4. Luisa Schonhaut, Iván Armijo, Marcela Pérez (2015) Gestational Age and Developmental Risk in Moderately and Late Preterm and Early Term Infants. Pediatrics 135(4): e835-e84.

5. Perri SS, Gary LD (2013) Clinical Review Preterm Birth and Neurodevelopment: A Review of Outcomes and Recommendations for Early Identification and Cost-effective Interventions. J of Tropical Pediatrics 59(4): 258-265.

6. Michael JG (2012) Preventive Interventions for Preterm Children Effectiveness and Developmental Mechanisms. J Dev Behav Pediatr 33(4): 352-364.

7. Alicia S, Jane O, Peter A, Roslyn B, Lex WD (2015) Early developmental intervention programmes post-hospital discharge to prevent motor and cognitive impairments in preterm infants. Cochrane Database Syst Rev 11: CD005945.

8. Nair MK, Philip E, Jeyaseelan L, George B, Mathews S, et al. (2009) Effect of Child Development Centre Model Early Stimulation Among At-risk Babies- A Randomized Controlled Trial Indian. Pediatrics 46: 20-26.
9. Guasch XD, Torrent FR, Martínez-Nadal S, Cerén CV, Saco MJ, et al. (2009) Late preterm infants: A population at underestimated risk. An Pediatr(Barc) 71(4): 291-298.

10. Lackman F, Vivian Capewell, Richardson B, da Silva O, Robert G, et al. (2001) The risks of spontaneous preterm delivery and perinatal mortality in relation to size at birth according to fetal versus neonatal growth standards. Am J Obst Gynecol 184(5): 946-953.

11. Carrie SM, Milton K, Wanda B, Carol AD, Hafsatou D, et al. (2013) Enrolment in Early Intervention Programs Among Infants Born Late Preterm, Early Term, and Term. Pediatrics 132(1): e61-e69.

12. Engle WA, Tomashek KM, Wallman C (2007) Committee on Fetus and Newborn, American Academy of Pediatrics. "Latepreterm" infants: a population at risk. Pediatrics 120(6): 1390-1401.

13. Vanderveen JA, Bassler D, Robertson CMT, Kirpalani H (2009) Early interventions involving parents to improve neurodevelopmental outcomes of premature infants: a meta-analysis. Journal of Perinatology 29: 343-351.

\section{Your next submission with Juniper Publishers will reach you the below assets}

- Quality Editorial service

- Swift Peer Review

- Reprints availability

- E-prints Service

- Manuscript Podcast for convenient understanding

- Global attainment for your research

- Manuscript accessibility in different formats

( Pdf, E-pub, Full Text, Audio)

- Unceasing customer service

Track the below URL for one-step submission https://juniperpublishers.com/online-submission.php 